\title{
Vanadium(V/IV)-Transferrin Binding Disrupts the Transferrin Cycle and Reduces Vanadium Uptake and Anti-Proliferative Activity in Human Lung Cancer Cells
}

\author{
Aviva Levina* ${ }^{*}$ and Peter A. Lay*a,b \\ ${ }^{a}$ School of Chemistry and ${ }^{b}$ Sydney Analytical, The University of Sydney, Sydney NSW 2006, \\ Australia \\ E-mails: aviva.levina@sydney.edu.au; peter.lay@sydney.edu.au
}

Supporting Information 
Table S1. Gel densitometry results for TBE-urea gel electrophoresis ${ }^{a}$

\begin{tabular}{|c|c|}
\hline Lane $^{b}$ & Bands $^{c}$ \\
\hline (a) 1 & 154 (6.9); 0.214 (55.1); 0.243 (25.5); 0.314 (7.2); 0.427 (5.3) \\
\hline (a) 2 & 0.220 (21.9); $0.327(28.6) ; 0.352(10.6) ; 0.434(2.9) ; 0.695(36.0)$ \\
\hline (a) 3 & $0.707(69.2) ; 0.754(30.8)$ \\
\hline (a) 4 & $\begin{array}{l}0.091(0.1) ; 0.161(1.8) ; 0.227(33.8) ; 0.252(21.9) ; 0.338(7.8) ; 0.445(9.6) ; 0.509 \\
(23.7) ; 0.707(0.8)\end{array}$ \\
\hline (a) 5 & $\begin{array}{l}0.102(0.3) ; 0.230(17.3) ; 0.287 \text { (41.3); } 0.338(15.3) ; 0.446 \text { (1.7); } 0.521 \text { (22.1); } 0.713 \\
(1.9)\end{array}$ \\
\hline (a) 6 & $\begin{array}{l}0.105(0.0) ; 0.230(12.2) ; 0.286(38.7) ; 0.339(18.6) ; 0.446(2.0) ; 0.529 \text { (23.9); } 0.718 \\
(4.6)\end{array}$ \\
\hline (a) 7 & $0.111(0.6) ; 0.514(16.1) ; 0.670(10.7) ; 0.720$ (48.2); 0.764 (24.4) \\
\hline (a) 8 & $0.118(0.8) ; 0.525$ (18.8); $0.718(51.9) ; 0.762(28.6)$ \\
\hline (a) 9 & $0.113(0.1) ; 0.532(14.3) ; 0.713(54.2) ; 0.755(31.3)$ \\
\hline (a) 10 & $0.113(0.9) ; 0.525(99.1)$ \\
\hline (b) 1 & $0.151(7.7) ; 0.220(54.1) ; 0.243(27.3) ; 0.325(8.5) ; 0.448(2.5)$ \\
\hline (b) 2 & $0.219(21.0) ; 0.242(6.2) ; 0.333(29.4) ; 0.453(3.6) ; 0.725(39.8)$ \\
\hline (b) 3 & $0.733(64.9) ; 0.780(35.1)$ \\
\hline (b) 4 & $0.088(1.3) ; 0.145(1.7) ; 0.219(35.6) ; 0.247(35.4) ; 0.333(11.3) ; 0.519$ (15.6) \\
\hline (b) 5 & $\begin{array}{l}0.084 \text { (1.1); } 0.147 \text { (1.8); } 0.215 \text { (19.9); } 0.242 \text { (15.3); } 0.264 \text { (28.6); } 0.331 \text { (15.2); } 0.529 \\
(18.2)\end{array}$ \\
\hline (b) 6 & $\begin{array}{l}0.082(0.7) ; 0.149(1.5) ; 0.215(16.3) ; 0.238 \text { (17.6); } 0.264 \text { (28.3); } 0.328 \text { (19.1); } 0.526 \\
(16.4)\end{array}$ \\
\hline (b) 7 & $\begin{array}{l}0.081(0.9) ; 0.210(13.9) ; 0.234(6.3) ; 0.301 \text { (2.5); } 0.331 \text { (29.3); } 0.361 \text { (16.2); } 0.515 \\
(16.0) ; 0.728 \text { (15.0) }\end{array}$ \\
\hline (b) 8 & $\begin{array}{l}0.077(0.9) ; 0.206(12.8) ; 0.228(7.0) ; 0.295(1.5) ; 0.324 \text { (19.7); } 0.353 \text { (11.2); } 0.469 \\
(6.0) ; 0.518 \text { (15.5); } 0.724(25.3)\end{array}$ \\
\hline (b) 9 & $\begin{array}{l}0.076(1.0) ; 0.203(14.0) ; 0.226(6.2) ; 0.288 \text { (1.6); } 0.317 \text { (21.4); } 0.347 \text { (12.4); } 0.461 \\
(5.7) ; 0.513 \text { (12.8); } 0.713(25.0)\end{array}$ \\
\hline (b) 10 & $0.066(2.7) ; 0.271(18.4) ; 0.494(78.9)$ \\
\hline
\end{tabular}


${ }^{a}$ Densitometry results (ImageLab 5.2, automatic band detection, high sensitivity) for the gels shown in Figure 4, main text. The corresponding gel profiles are shown in Figures S1 and S2. $b$ The designations (a) and (b) correspond to those in Figures $4 \mathrm{a}$ and $4 \mathrm{~b}$ (main text), respectively. The conditions used for the corresponding lanes are listed in the caption of Figure 4 (main text). ${ }^{c}$ These numbers show the relative front $\left(R_{\mathrm{f}}\right)$ positions from the top of the gel, see Figures $\mathrm{S} 1$ and $\mathrm{S} 2$. The numbers in parentheses are the relative intensities (\%) of each band. 
Table S2. Calculated kinetic and thermodynamic parameters of Tf binding to TfR1-loaded BLI probes in dilute cell culture media

\begin{tabular}{|c|c|c|c|c|c|c|c|}
\hline \multirow[t]{2}{*}{ Step $^{b}$} & \multirow[t]{2}{*}{ Parameter $^{c}$} & \multicolumn{6}{|c|}{ Experiment } \\
\hline & & $F e_{2} T f$, no $V$ & $\mathrm{Fe}_{2} \mathrm{Tf}, \mathrm{V}(\mathrm{V})$ & $\mathrm{Fe}_{2} \mathrm{Tf}, \mathrm{V}(\mathrm{IV})$ & $\mathrm{Fe}_{0.5} \mathrm{Tf}$, no V & $\mathrm{Fe}_{0.5} \mathrm{Tf}, \mathrm{V}(\mathrm{V})$ & $\mathrm{Fe}_{0.5} \mathrm{Tf}, \mathrm{V}(\mathrm{IV})$ \\
\hline \multirow[t]{3}{*}{$\mathbf{A}$} & seq. $k_{1}, \mathrm{~s}^{-1}(\%)$ & $0.41(47)$ & $0.39(41)$ & $0.29(51)$ & $0.34(42)$ & $0.40(25)$ & $0.34(36)$ \\
\hline & seq. $k_{2}, \mathrm{~s}^{-1}(\%)$ & $0.090(30)$ & $0.14(28)$ & $0.060(30)$ & $0.096(32)$ & $0.14(38)$ & $0.11(24)$ \\
\hline & par. $k_{3}, \mathrm{~s}^{-1}(\%)$ & $0.019(23)$ & $0.031(31)$ & $0.021(19)$ & $0.019(26)$ & $0.025(27)$ & $0.025(30)$ \\
\hline \multirow[t]{4}{*}{ B } & par. $k_{1}, \mathrm{~s}^{-1}(\%)$ & -- & -- & $0.33(1)$ & $0.028(19)$ & $0.022(28)$ & $0.023(27)$ \\
\hline & par. $k_{2}, \mathrm{~s}^{-1}(\%)$ & $1.1 \times 10^{-3}(100)$ & $1.1 \times 10^{-3}(100)$ & $1.4 \times 10^{-3}(99)$ & $1.6 \times 10^{-3}(81)$ & $2.4 \times 10^{-3}(72)$ & $1.8 \times 10^{-3}(73)$ \\
\hline & $K_{\mathrm{D} 1}, \mathrm{nM}^{d}$ & 2.7 & 2.8 & 4.8 & -- & -- & -- \\
\hline & $K_{\mathrm{D} 2}, \mathrm{nM}^{d}$ & 12 & 7.9 & 23 & - & -- & - \\
\hline $\mathbf{C}$ & $k_{1}, \mathrm{~s}^{-1}$ & $7.5 \times 10^{-4}(100)$ & $7.7 \times 10^{-4}(100)$ & $9.1 \times 10^{-4}(100)$ & $6.6 \times 10^{-4}(100)$ & $7.6 \times 10^{-4}(100)$ & $6.9 \times 10^{-4}(100)$ \\
\hline \multirow[t]{3}{*}{ D } & par. $k_{1}, \mathrm{~s}^{-1}(\%)^{e}$ & $1.08(74)$ & $1.4(23)$ & $1.4(32)$ & $1.4(70)$ & $2.0(18)$ & $1.5(26)$ \\
\hline & par. $k_{2}, \mathrm{~s}^{-1}(\%)^{e}$ & $0.13(26)$ & $0.080(27)$ & $0.035(68)$ & $0.22(30)$ & $0.076(26)$ & $0.088(14)$ \\
\hline & par. $k_{3}, \mathrm{~s}^{-1}(\%)^{e}$ & -- & $7.3 \times 10^{-3}(50)$ & -- & -- & $5.9 \times 10^{-3}(56)$ & $2.7 \times 10^{-3}(50)$ \\
\hline
\end{tabular}

${ }^{a}$ Cell culture media (Advanced DMEM with $2 \%$ vol. FCS) containing added $\mathrm{Fe}_{2} \mathrm{Tf}(30 \mu \mathrm{M})$, or $\mathrm{Fe}_{0.5} \mathrm{Tf}(30 \mathrm{mM}$ apoTf $+15 \mu \mathrm{M} \mathrm{Fe}(\mathrm{III})-\mathrm{NTA})$ in the absence or presence of $\mathrm{V}(\mathrm{V})$ or $\mathrm{V}(\mathrm{IV})\left(\mathrm{Na}_{3} \mathrm{VO}_{4}\right.$ or $\mathrm{VOSO}_{4}$, respectively, $\left.80 \mu \mathrm{M} \mathrm{V}\right)$ were collected after experiments with A549 cells (16 h pre-equilibration and $72 \mathrm{~h}$ treatment at $310 \mathrm{~K}$ and $\left.5 \% \mathrm{CO}_{2}\right)$, then diluted 30 -fold with binding buffer $\left(20 \mathrm{mM} \mathrm{HEPES}, 25 \mathrm{mM} \mathrm{NaHCO}_{3}, 140\right.$ $\mathrm{mM} \mathrm{NaCl}, \mathrm{pH} 7.4)^{34}$ immediately prior to BLI measurements. ${ }^{b}$ Designations of the steps correspond to those used in previous articles ${ }^{32-34}$ and in Figures 5 (main text), S3 and S4: $\mathbf{A}$ is the binding of Tf to TfR1 immobilized on BLI probe surface (using cell culture medium diluted with binding buffer to $[\mathrm{Tf}]=1.0 \mu \mathrm{M}$ ); $\mathbf{B}$ is the dissociation of Tf from TfR1 at $\mathrm{pH} 7.4$ (using binding buffer alone); $\mathbf{C}$ is the removal of Fe from the 
Tf-TfR1 adduct under endosomal conditions (100 mM MES, $300 \mathrm{mM} \mathrm{KCl,} 0.10 \mathrm{mM}$ citrate, $\mathrm{pH} 5.6) ;{ }^{34}$ and $\mathbf{D}$ is the post-endosomal dissociation of Tf from TfR1 at pH 7.4 (binding buffer). ${ }^{c}$ Fitting of kinetic curves with one to three first-order processes (seq. for sequential, par. for parallel), based on the previous studies. ${ }^{34}$ Numbers in parentheses indicate the $\%$ contributions of each step into overall kinetics. ${ }^{d}$ Dissociation constants for the sequential binding of first and second $\mathrm{Fe}_{2} \mathrm{Tf}$ molecules to the TfR1 dimer on BLI probe surface $\left(K_{\mathrm{D} 1}=k_{2}{ }^{\mathrm{B}}[\mathrm{Tf}] / \mathrm{k}_{1}{ }^{\mathrm{A}} ; K_{\mathrm{D} 2}=\right.$ $\left.k_{2}{ }^{\mathrm{B}}[\mathrm{Tf}] / k_{2}{ }^{\mathrm{A}}\right) .{ }^{27}$ The binding affinities were lower than those reported previously for $\mathrm{Fe}_{2} \mathrm{Tf}-\mathrm{TfR} 1$ binding in aqueous buffer solutions $\left(K_{\mathrm{D} 1}=0.7 \pm\right.$ $\left.0.1 \mathrm{nM} ; K_{\mathrm{D} 2}=3.2 \pm 0.6 \mathrm{nM}\right)^{34}$ due to the $\sim 3$-fold higher dissociation rates in step B. This difference is probably due to partial Fe(III) removal from $\mathrm{Fe}_{2} \mathrm{Tf}$ in cell culture medium in the presence of strong $\mathrm{Fe}(\mathrm{III})$ complexing agents, such as phosphate and amino acids. ${ }^{56}$ The kinetics of steps $\mathbf{A}, \mathbf{C}$ and $\mathbf{D}$ were consistent with those reported previously. ${ }^{34}$ The $K_{\mathrm{D}}$ values were not determined for the experiments using partially Fesaturated $\mathrm{Tf}$, because they combine the binding and dissociation of $\mathrm{Fe}_{2} \mathrm{Tf}, \mathrm{Fe}_{C} \mathrm{Tf}, \mathrm{Fe}_{N} \mathrm{Tf}$ and apoTf. ${ }^{41} e$ The $k_{1}, k_{2}$ and $k_{3}$ values correspond to the fast, medium or slow dissociation of apoTf, MTf or $\mathrm{M}_{2} \mathrm{Tf}(\mathrm{M}=\mathrm{Fe}$ or $\mathrm{V})$, respectively, from TfR1 at $\mathrm{pH}$ 7.4. ${ }^{34}$ 
Lanes 1-5
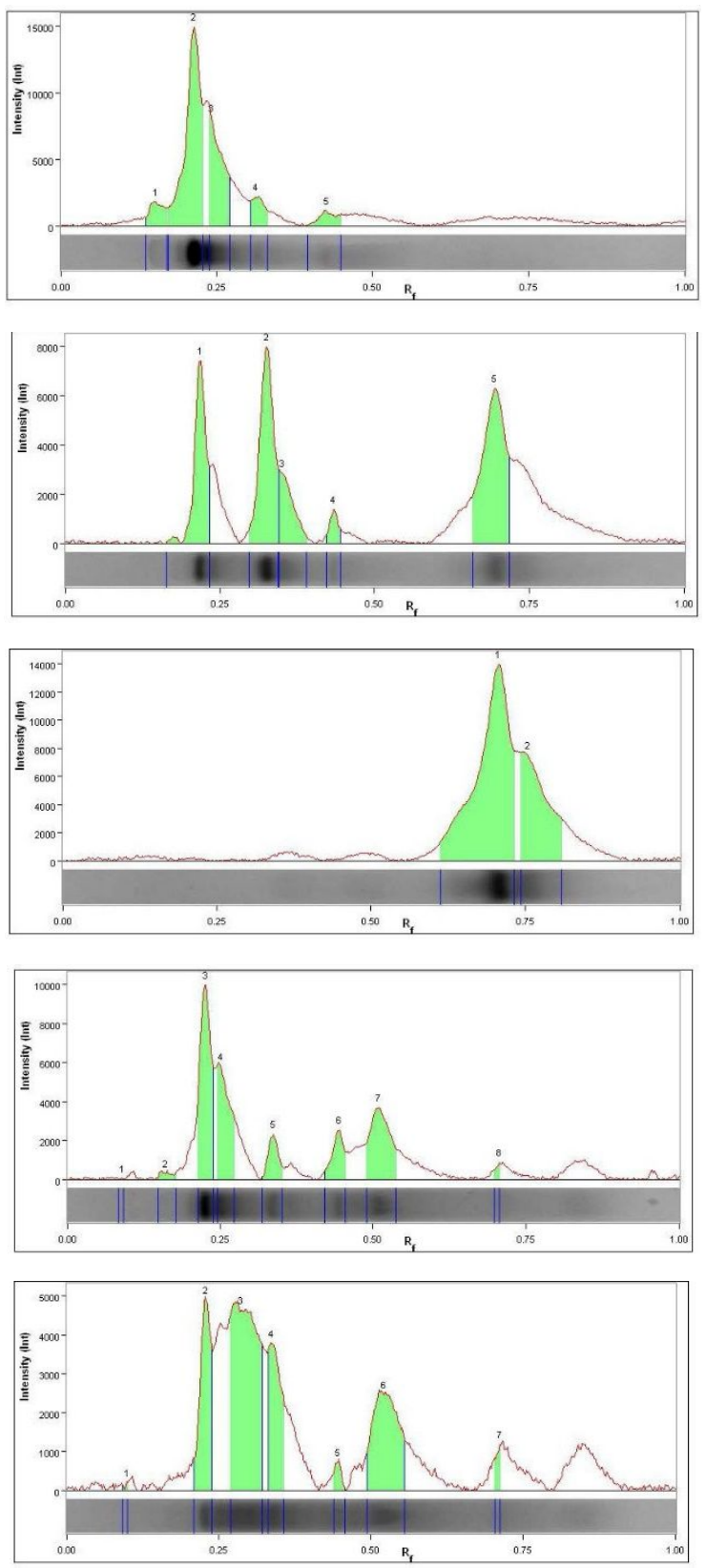

Lanes 6-10
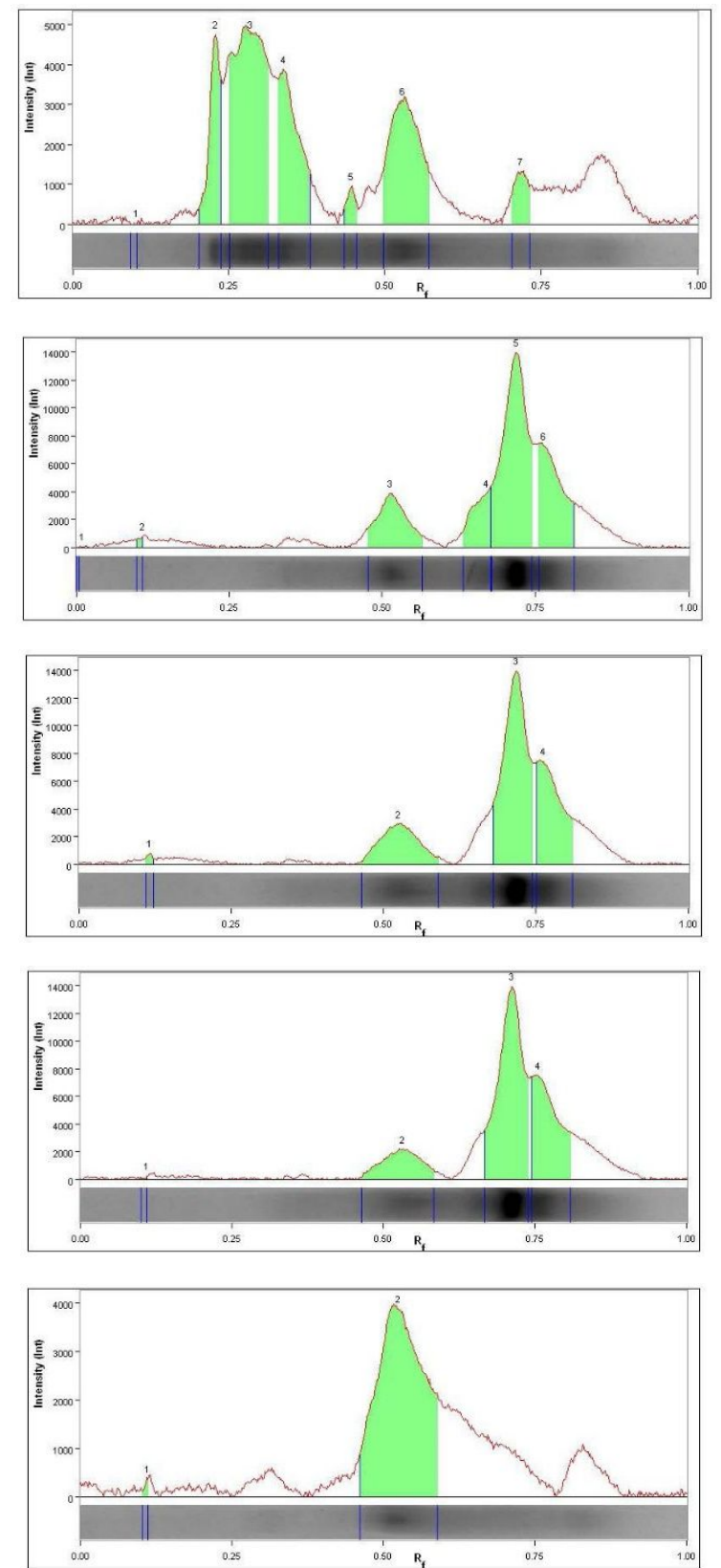

Figure S1. Gel densitometry results for Figure 4a (main text), see Table S1 for details. Analysis performed using ImageLab 5.2 software (BioRad Laboratories, 2014) with automatic band detection at the high sensitivity mode. 
Lanes 1-5
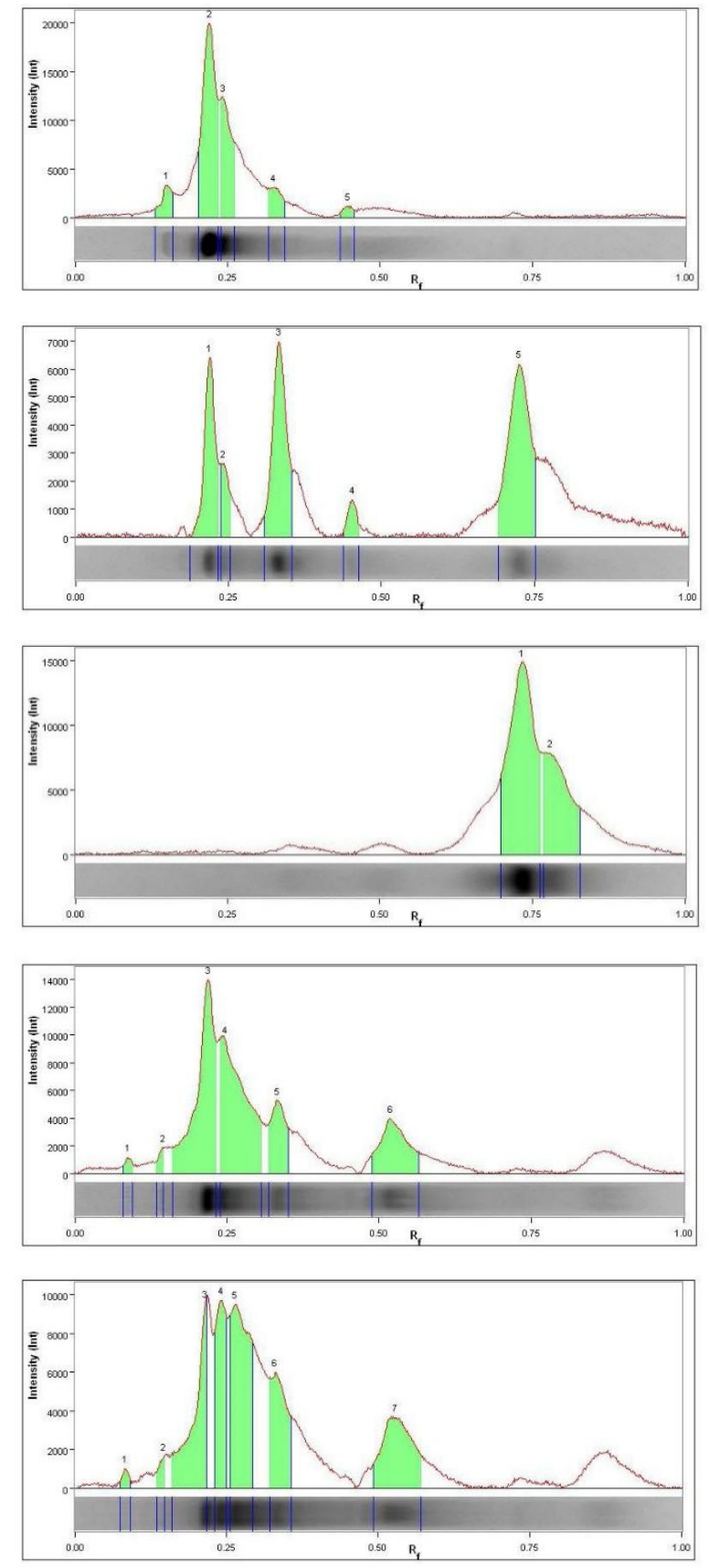

Lanes 6-10
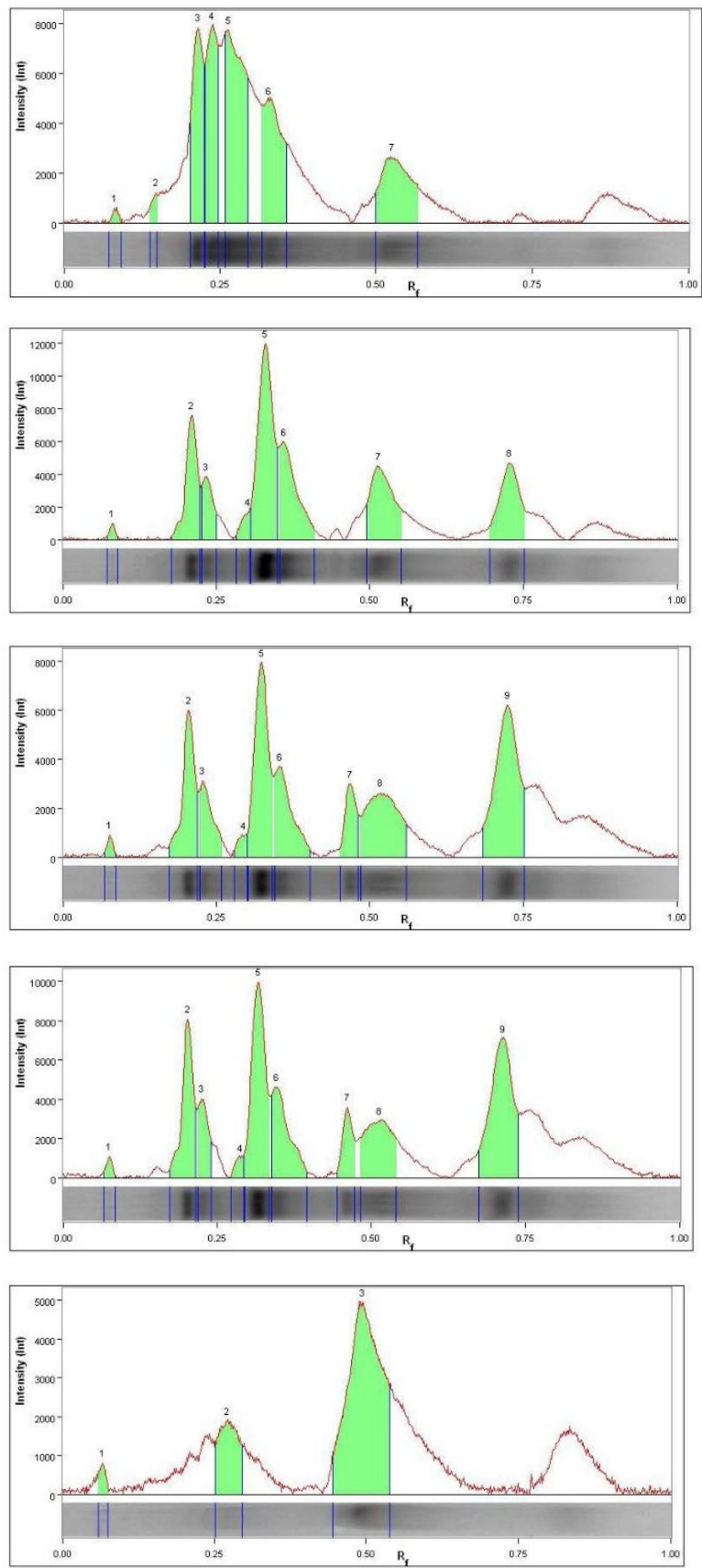

Figure S2. Gel densitometry results for Figure 4b (main text), see Table S1 for details. Analysis performed using ImageLab 5.2 software (BioRad Laboratories, 2014) with automatic band detection at the high sensitivity mode. 


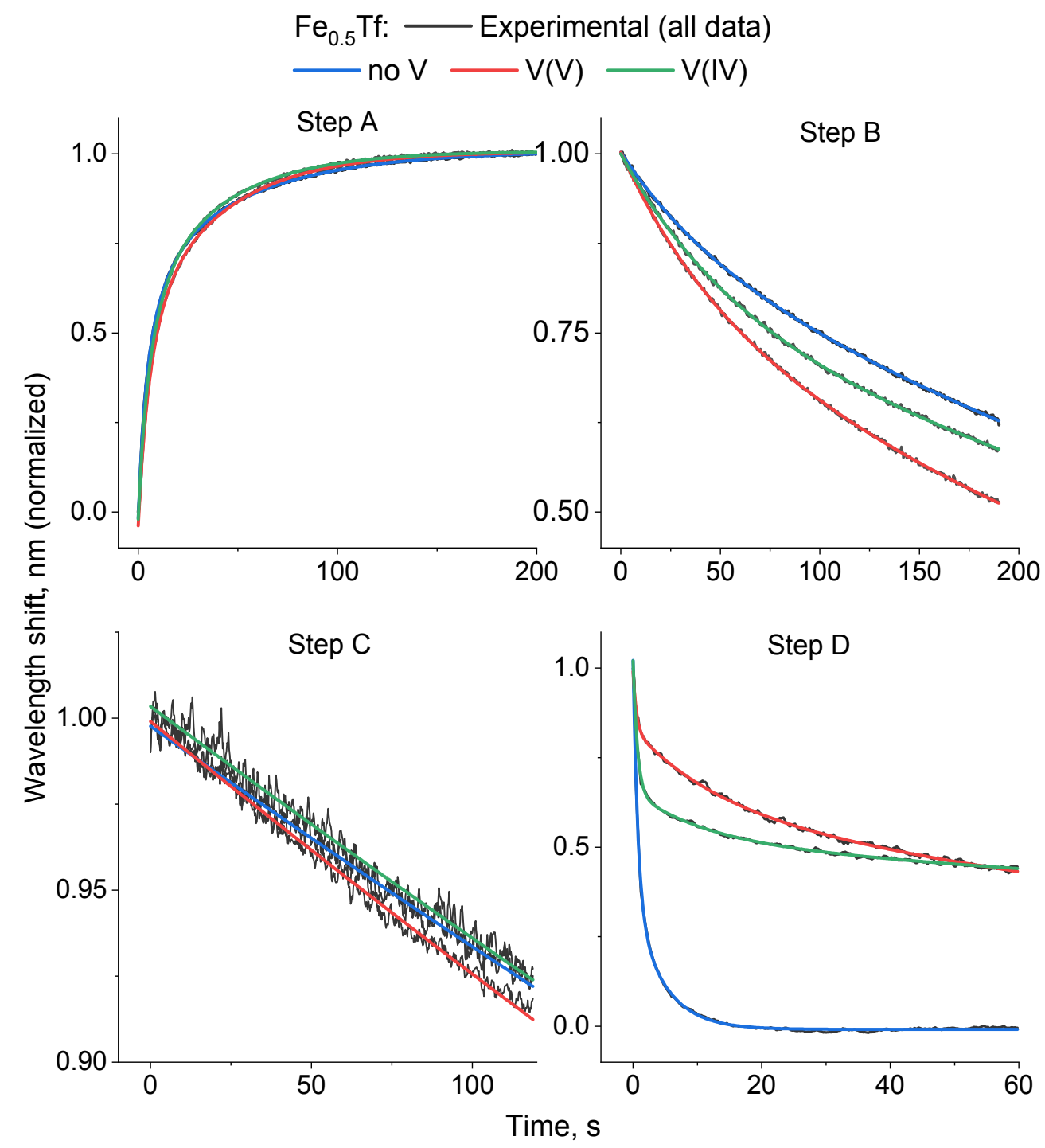

Figure S3. Effect of added V(V) or V(IV) $(80 \mu \mathrm{M})$, pre-equilibrated with cell culture medium containing $30 \mu \mathrm{M}$ of $\mathrm{Fe}_{0.5} \mathrm{Tf}$, on the BLI assays. Designations of steps A-D correspond to those in Figure 5, main text. Experimental data are shown in black lines, and the fits obtained in kinetic analyses (Table S2) are shown in colored lines. 


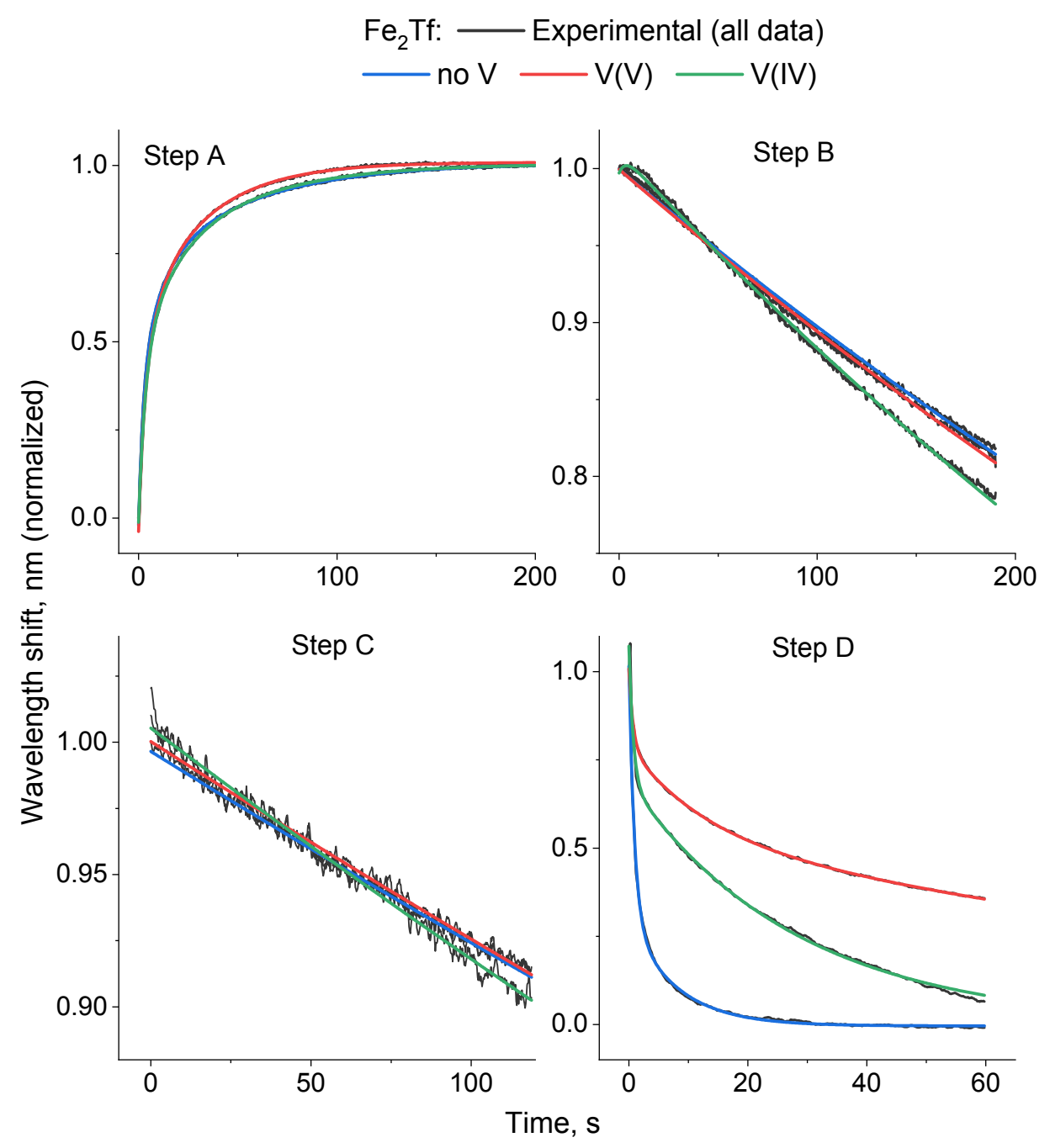

Figure S4. Effect of added V(V) or V(IV) $(80 \mu \mathrm{M})$, pre-equilibrated with cell culture medium containing $30 \mu \mathrm{M}$ of $\mathrm{Fe}_{2} \mathrm{Tf}$, on the BLI assays. Designations of steps A-D correspond to those in Figure 5, main text. Experimental data are shown in black lines, and the fits obtained in kinetic analyses (Table S2) are shown in colored lines. 